\title{
Gas Exchange During Exercise in Different Evolutional Stages of Chronic Chagas' Heart Disease
}

\author{
Fátima Palha de Oliveira, Roberto Coury Pedrosa, Antonio Giannella-Neto
}

Rio de Janeiro, RJ - Brazil

\begin{abstract}
Objective - To compare gas exchange at rest and during exercise in patients with chronic Chagas' heart disease grouped according to the Los Andes clinical/hemodynamic classification.
\end{abstract}

Methods - We studied 15 healthy volunteers and 52 patients grouped according to the Los Andes clinical/hemodynamic classification as follows: 17 patients in group IA (normal electrocardiogram/echocardiogram), 9 patients in group IB (normal electrocardiogram and abnormal echocardiogram), 14 patients in group II (abnormal electrocardiogram/echocardiogram, without congestive heart failure), and 12 patients in group III (abnormal electrocardiogram/echocardiogram with congestive heart failure). The following variables were analyzed: oxygen consumption $\left(V_{\mathrm{O}_{2}}\right)$, carbon dioxide production $\left(V_{\mathrm{CO}_{2}}\right)$, gas exchange rate $(R)$, inspiratory current volume $\left(V_{I C}\right)$, expiratory current volume $\left(V_{E C}\right)$, respiratory frequency, minute volume $\left(V_{E}\right)$, heart rate $(H R)$, maximum load, $\mathrm{O}_{2}$ pulse, and ventilatory anaerobic threshold (AT).

Results - When compared with the healthy group, patients in groups II and III showed significant changes in the following variables: $V_{\text {O2peak }} V_{\text {CO2peak }}, V_{\text {ICpeak }}, V_{E \text { Cpeak }}{ }, H R$, and maximum load. Group IA showed significantly better results for these same variables as compared with group III.

Conclusion - The functional capacity of patients in the initial phase of chronic Chagas ' heart disease is higher than that of patients in an advanced phase and shows a decrease that follows the loss in cardiac-hemodynamic performance.

Key words: chronic Chagas' heart disease, cardiopulmonary exercise test, oxygen consumption.

Hospital Universitário Clementino Fraga $\mathrm{F}^{\circ}$ - UFRJ

Mailing address: Fátima Palha de Oliveira - Rua das Laranjeiras, 136/203 - 22240000 - Rio de Janeiro, RJ, Brazil - e-mail: Palha@alternex.com.br

English version by Stela Maris C. Gandour
Even though quantifying the response to exercise in patients with heart diseases of different etiologies has been the aim of many studies, those studing alterations in the functional capacity of patients with the cardiac form of Chagas' disease are scarce. However, quantification and analysis of the functional capacity in different phases of chronic chagasic heart disease are of practical interest because they generate precise information about the oxygen capacity of transportation and use, i.e., the functional capacity of the lungs and the cardiovascular, muscular, and metabolic systems combined. This assessment provides the clinician with data for establishing a prognosis ${ }^{1}$, and it is important in the follow-up of the therapeutical response and evaluation of the adaptation of these patients during a rehabilitation program. Based on oxygen consumption $\left(V_{\mathrm{O} 2}\right)$ and the anaerobic threshold reached during the cardiopulmonary exercise test, the clinician can decide whether the patient is qualified or not for a study ${ }^{2}$ and can orient the appropriate level of the patient's daily activities. This along with the analysis of other parameters may provide the clinician with information for deciding whether a cardiac transplantation is necessary ${ }^{3,4}$.

The present study aims to quantify and analyze the gas exchange at rest and during exercise in patients with chronic Chagas' heart disease relating the results to the stage of the disease according to the modified Los Andes clinical/hemodynamic classification ${ }^{5,6}$ (diagram I).

\section{Methods}

As part of the present study developed during 1997 and 1998, we evaluated 15 healthy male volunteers (age range: from 22 to 51 years; mean age $=36 \pm 9$ years) who constituted the control group $(\mathrm{N})$. These volunteers did not take part in any systematic physical training program, even though some reported the practice of sporadic physical activities. This group comprised 4 postgraduate students, 8 from the staff of the federal university of Rio de Janeiro, and 3 remaining volunteers who did not belong to the university community. These healthy volunteers underwent 2 cardio- 


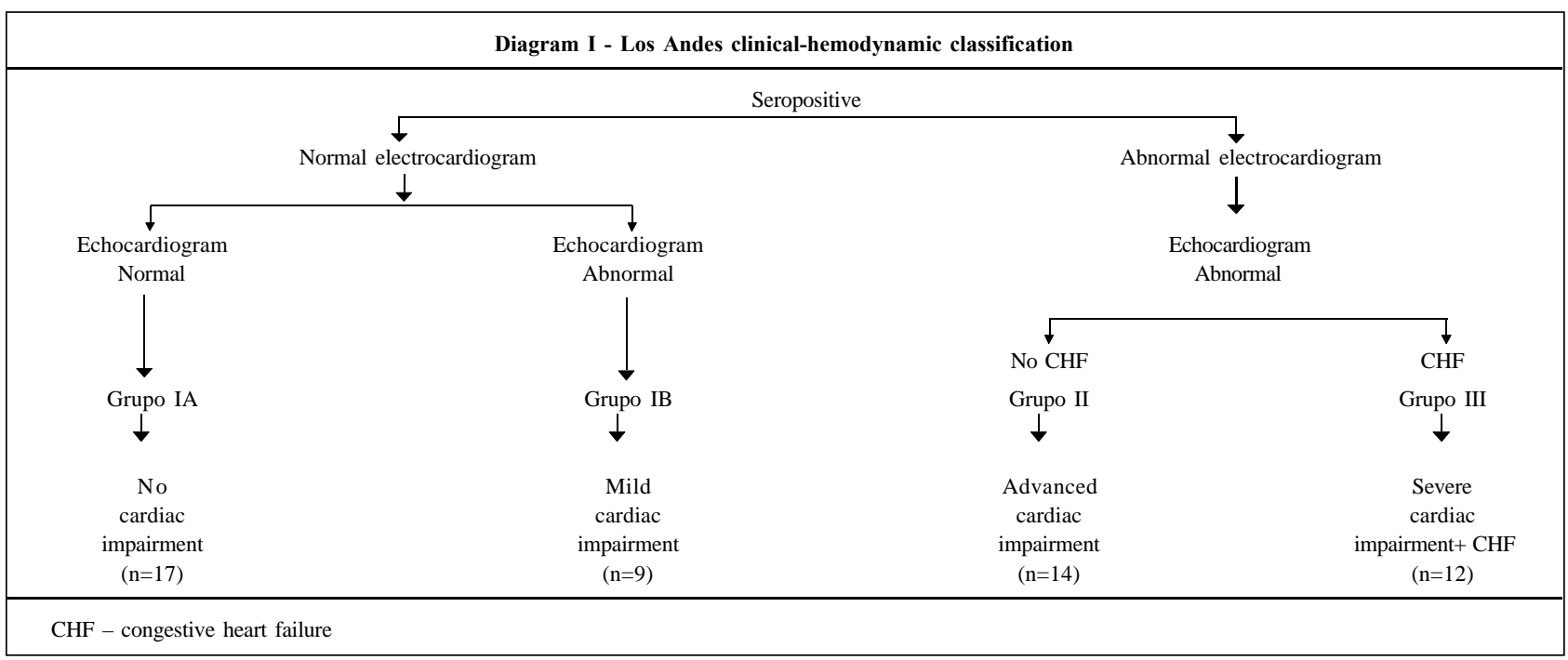

pulmonary exercise tests one week apart. The results of these 2 tests were used for analyzing the reproducibility of the measurements of gas exchange performed at the laboratory, which generated satisfactory results allowing the patients to start their tests. The result of the first test in the healthy group was used for comparison with the results of the patients in the other groups.

Patients for the study were selected among the 200 patients followed up in the cardiology outpatient clinics for Chagas' heart disease of the HUCFF and was based on the following exclusion criteria: patients with hypertension, chronic obstructive pulmonary disease, cardiomyopathy of any other type or cause, thyroid dysfunction, known immunological dysfunction, rheumatic valvar disease, congenital heart disease, coronary artery disease, patients with cardiac pacemakers, patients with neuromuscular disorders, athletes, and patients who did not reach the anaerobic threshold when undergoing the test.

All patients selected were males with ages ranging from 20 to 72 years (mean of $50 \pm 11$ years). They had positive indirect hemagglutination reaction and indirect immunofluorescence for T. cruzi. They had no other associated diseases and had a stable clinical condition for the last 3 months. They were grouped according to the Los Andes clinical/hemodynamic classification (diagram I), which is based on electrocardiographic, echocardiographic (Mmode and two-dimensional echocardiogram with intracavitary Doppler), and physical examination findings. Electrocardiographic changes were classified according to the New York Heart Association criteria. The Minnesota code modified for Chagas' heart disease ${ }^{7}$ was used to standardize the electrocardiogram interpretation. The echocardiographic assessment consisted of the analysis of the segmentary cardiac function of the patients, and it was expressed as systolic thinning or deficit of thickening. The diastolic dysfunction was expressed according to the standard "deficit of relaxation" and "restrictive pattern" ${ }^{8}$. Left ventricular ejection fraction was calculated by the method of
Teicholz et al ${ }^{9}$. Three observers analyzed the tests (echocardiogram and electrocardiogram) and, in case of discordance between them, another reading was performed by one of the researchers to get a definitive result. The diagnosis of congestive heart failure met the criteria of the Framingham Heart Study ${ }^{10}$.

The patients were classified into groups according to the Los Andes classification as follows: 17 patients in group IA (normal electrocardiogram and echocardiogramno heart involvement), 9 patients in group IB (normal electrocardiogram and abnormal echocardiogram - mild heart involvement), 14 patients in group II (abnormal electrocardiogram and echocardiogram, without congestive heart failure - advanced heart involvement), and 12 patients in group III (abnormal electrocardiogram and echocardiogram with congestive heart failure - severe heart involvement). These patients were living in Rio de Janeiro at the time of the study but had been born in endemic areas for Chagas' disease $(47 \%$ had been born in Bahia State, $25 \%$ in Paraiba State, $16 \%$ in Ceará State, $5 \%$ in Minas Gerais State, and 1 patient had been born in Rio de Janeiro State) and had been away from endemic areas for more than 20 years. In the medical visit prior to the cardiopulmonary exercise test, the patients using medications were instructed to suspend them 48 hours prior to the test. No clinical problems occurred during the study.

This study was approved by the local Ethics Committee (HUCFF) abiding by the national and international guidelines for research on human beings (1995), which regulate experiments with humans. The patients underwent the tests only after written consent.

Protocol of exercise - A Monark mechanical cycloergometer was used in a continuous test with loads increasing ( 15 watts) every minute. This protocol was chosen because it is better tolerated by the patients and because it allows reaching high ${ }_{\mathrm{O} 2}$ values with a total test duration of 8 to 10 minutes ${ }^{11}$. The pedal frequency was fixed as 60 rotations per minute. The exercise period was preceded by a 4 -minute 
rest and a 2-minute warm-up with zero load, and followed by a 12-minute recovery, 3 minutes of which were in the active form ( 25 watts) and 9 minutes in the passive form. Electrocardiographic signals (SDM2000, Dixtal) and heart rate were recorded during the entire test, which was interrupted in the presence of symptoms hindering its continuity or that represented risk for the patient, or both. We analyzed only the tests in which the patients reached the anaerobic threshold to assure all patients reached a submaximal exercise level during the test.

Temporal concentrations of inspired and expired gases at each respiratory cycle were measured with a rapid gas analyzer (Airspec MGA 2000 respiratory mass spectrometer) from the sample suctioned continuously next to the mouthpiece used by the patient. The respiratory mass spectrometer was calibrated by linear adjustment with 2 known gas mixtures.

Flow measurement was performed with a Fleisch number 3 pneumotachograph warmed to $36^{\circ} \mathrm{C}$ coupled with a transducer of differential pressure (Micro-Switch 163PC01D36). Equipment calibration (respiratory mass spectrometer, pneumotachograph, and cycloergometer) was performed on a daily basis before each test. An IBM-PC 486 microcomputer was used for experiment acquisition, analysis, and recording.

Signals of gas flow and concentration were sampled at a rate of $60 \mathrm{~Hz}$ by the analogical-digital converter of the respiratory mass spectrometer. The VIT 2000 software employed for processing the signals and calculating the cardiopulmonary exercise test parameters was developed and tested in the laboratory of pulmonary engineering of the Biomedical Engineering Program of COPPE-UFRJ ${ }^{12}$. The flow signal was calculated with a third-order polynomial adjustment ${ }^{13}$, and the gas sample suctioned during the analysis of gas concentrations was compensated by the respiratory mass spectrometer $\left(1 \mathrm{~mL} \cdot \mathrm{s}^{-1}\right) . \mathrm{V}_{\mathrm{IC}}$ and $\mathrm{V}_{\mathrm{EC}}$ were calcu- lated through trapezoidal numerical integration and expressed in BTPS $\left(37^{\circ} \mathrm{C}, 760 \mathrm{mmHg}\right.$, and saturated with water vapor) for each respiratory cycle. Instantaneous gas viscosity was calculated and employed to correct its effect in gas flows and volumes ${ }^{13}$, and to estimate the time delay between gas flow and concentrations ${ }^{14}$ necessary for calculating the partial respiratory gas volumes. These were expressed in STPD $\left(0^{\circ} \mathrm{C}, 760 \mathrm{mmHg}\right.$, dry $)$ and obtained by numerical integration of the product of the gas flow and fractions, and these signals were previously synchronized. As these measurements were taken at the mouth, the estimation of alveolar gas exchanges was performed compensating the variations in the functional residual capacity through measurements of the nitrogen gas ${ }^{15}$. The $V_{\mathrm{O} 2}$ and $V_{\mathrm{CO} 2}$ were calculated through the product of the volumes at each cycle and the instant respiratory frequency, and expressed in STPD.

Diagram II shows the variables analyzed ( 9 at rest and 17 during exercise). The values computed for the variables at rest correspond to the mean of the last 30 seconds of the period, which has a total length of 4 minutes, when the respiratory signals are already stabilized.

The response to exercise of patients with heart disease is usually deficient because of limitations in the $\mathrm{O}_{2}$ transport system inherent to these patients, leading to an early commencement of fatigue and interruption of the test. Therefore, to reach $V_{\mathrm{O} 2} \max$, which is defined as the saturation of the capacity of $\mathrm{O}_{2}$ uptake and transport for the muscles during exercise, is difficult and involves some risks in some cases. Therefore, in our study we adopted $\mathrm{V}_{\text {O2peak }}$ (mean of the last 30 seconds of the last load of the exercise) as an index of response to exercise of patients with Chagas' heart disease.

The anaerobic threshold (AT) was expressed in regard to $V_{\mathrm{O} 2}$ in $\mathrm{mL} \cdot \mathrm{min}^{-1}$ (STPD) and was identified by 2 ventilatory methods and denominated anaerobic threshold in all stages of the study: AT 1 - value of $V_{\mathrm{O} 2}$ in which the respira-

\begin{tabular}{|c|c|c|}
\hline \multicolumn{3}{|c|}{ Diagram II - Description of the controlled variables } \\
\hline Variable & Abbreviation & Unit \\
\hline Absolute oxygen consumption & $V_{\mathrm{O} 2}$ & ml.min ${ }^{-1}$ (STPD) \\
\hline Relative oxygen consumption & $V_{\mathrm{O} 2} /$ body mass & $\mathrm{ml} \cdot \mathrm{kg}^{-1} \cdot \mathrm{min}^{-1}(\mathrm{STPD})$ \\
\hline$\%$ do $V_{\text {O2máx }}$ expected for age & $\% V_{\text {O2máx }}$ expected & $\%$ \\
\hline Carbon dioxide production & $V_{\mathrm{CO} 2}$ & $\mathrm{ml} / \mathrm{min}^{-1}$ (STPD) \\
\hline Gas exchange rate & $\mathrm{R}=V_{\mathrm{CO} 2} / V_{\mathrm{O} 2}$ & \\
\hline Inspiratory current volume & $V_{\mathrm{CI}}$ & $\mathrm{ml}$ (BTPS) \\
\hline Expiratory current volume & $V_{\mathrm{CE}}$ & $\mathrm{ml}$ (BTPS) \\
\hline Respiratory frequency & Respiratory frequency & breaths. $\min ^{-1}$ \\
\hline Minute volume & $V_{\mathrm{E}}$ & ml.min ${ }^{-1}$ (BTPS) \\
\hline Heart rate & HR & bpm \\
\hline$\%$ maximum heart rate expected for age & $\%$ HRmax expected & $\%$ \\
\hline Oxygen pulse & $\mathrm{O}_{2}$ pulse $=V \mathrm{O}_{2} / \mathrm{HR}$ & mL.beats.min \\
\hline Absolute anaerobic threshold & $\mathrm{AT}$ & ml.min ${ }^{-1}$ (STPD) \\
\hline Relative anaerobic threshold & AT/body mass & $\mathrm{ml} \cdot \mathrm{kg}^{-1} \cdot \mathrm{min}^{-1}$ (STPD) \\
\hline$\%$ AT expected for age & $\%$ AT expected & $\%$ \\
\hline Anaerobic threshold in $\% V_{\text {O2peak }}$ & AT $\% V_{\text {O2peako }}$ & $\%$ \\
\hline Maximum load & Maximum load & Watts \\
\hline
\end{tabular}


tory exchange rate $\left(\mathrm{R}=V_{\mathrm{CO} 2} / V_{\mathrm{O} 2}\right)$ is equal to or higher than 1.0 and continues to increase in subsequent respiratory cycles $^{16,17,18}$; and AT2 - the point in which the ventilatory equivalent of $\mathrm{O}_{2}\left(V_{\mathrm{E}} / V_{\mathrm{O} 2}\right)$ increases without a concomitant increase in the ventilatory equivalent of $\mathrm{CO}_{2}\left(V_{\mathrm{E}} / V_{\mathrm{CO} 2}\right)^{11}$. In the first method (AT1), we were able to identify the anaerobic threshold for all patients, but in the second method, because of very noisy signals, we could only identify the anaerobic threshold for 30 patients. We compared the two results (AT1 and AT2) by the paired Student t test, which did not show a significant difference between the two measures for the $5 \%$ significance level $(\mathrm{p}=0.29)$. Therefore, for statistical purpose, we adopted AT1.

The statistical treatment was performed with the Statistical Analysis System (SAS). We used the one-way ANOVA analysis of variance and the Dunnet ( $\mathrm{N}$ patients) and Tukey (patient $x$ patient) tests of multiple comparisons to specify which groups differed from each other. The statistical significance level adopted in these analyses was 5\% $(\mathrm{p} \leq 0.05)$.

\section{Results}

Tables I and II show the clinical and laboratory findings of the groups studied.

In regard to the physical characteristics of the sample, individuals in group $\mathrm{N}$ had ages significantly $(\mathrm{p}=0.0001)$ lower than those in groups IA, II, and III, and their heights were significantly $(\mathrm{p}=0.04)$ higher than those of the individuals in group IB.

During the resting period, significant differences between group $\mathrm{N}$ and those of patients in regard to the variables $\mathrm{V}_{\text {ICrest }}$ and $\mathrm{V}_{\mathrm{EC}}$ rest and the respiratory frequency were observed. We also observed that $\mathrm{V}_{\mathrm{EC}}$ rest and $\mathrm{V}_{\mathrm{IC}}$ rest were higher in the individuals in group $\mathrm{N}$ than in the patients in other groups. The mean respiratory frequency was higher in group III (Table III).

The ages and heights of the patients with Chagas' heart disease studied did not differ. The body mass (body weight) of patients in groups IA and II, however, showed significant differences ( $\mathrm{p}=0.02)$ (Table III).

During exercise, when group $\mathrm{N}$ was compared with the groups of patients, those groups with more advanced disease (groups II and III) showed significant differences. For the maximum load variable only, a significant difference $(\mathrm{p}=0.004)$ was observed between the groups $\mathrm{N}$ and IA. Group $\mathrm{N}$ was different from IB only in regard to the variables $\mathrm{V}_{\text {ICpeak }}(\mathrm{p}=0.001)$ and AT\% $V_{\text {O2peak }}(\mathrm{p}=0.05)$ (Table IV).

Figure 2 depicts the relationship $\mathrm{V}_{\mathrm{E}} \mathrm{V}_{3} \mathrm{~V}_{\mathrm{co} 2}$ in a volunteer from group $\mathrm{N}$ and a patient from group III showing the greater ventilatory work for given level of $\mathrm{C}_{\mathrm{o} 2}$ production in comparison to the assymptomatic volunteer.

Heart rate at the end of exercise showed mean values in the groups that had decreases in those variables referenced above according to the increase in the degree of cardiac involvement (Table IV). The ANOVA analysis of variance, however, showed no significant difference between the mean heart rate when comparing the four groups of patients. No significant difference was found between the groups of patients for the variables $\mathrm{R}_{\text {peak }}$, respiratory frequency, and $V_{\text {Epeak }}($ Table IV).

\section{Discussion}

In regard to Chagas' heart disease in its chronic form, it is known that the intracellular lesions seen on endomyocardial biopsies are more marked in group IB than in group IA, where the lesions detected are minimum. Carrasco et al ${ }^{19}$ reported a high incidence $(60 \%)$ of microscopic changes in group IA, and the alterations in the contractile system in group IB were more prominent than those in group IA. Group II showed fibrosis and an inflammatory process, which were even more marked in group III. Despite the morphological findings reported in the study by Carrasco et al ${ }^{19}$, our study did not detect corresponding significant differences between the functional results of groups IA and IB

\begin{tabular}{|c|c|c|c|c|c|c|}
\hline & & $\begin{array}{c}\text { Groups } \\
N(n=15)\end{array}$ & IA $(n=17)$ & IB $(n=9)$ & II $(n=14)$ & III $(n=12)$ \\
\hline \multicolumn{7}{|l|}{ Echocardiogram } \\
\hline LVDDI & $\left(\mathrm{mm} / \mathrm{m}^{2}\right)$ & NA & $27 \pm 4$ & $28 \pm 3$ & $34 \pm 3$ & $43 \pm 4$ \\
\hline LVEF & $(\%)$ & NA & $68 \pm 4$ & $58 \pm 3$ & $48 \pm 8$ & $28 \pm 8$ \\
\hline \multicolumn{7}{|l|}{ ECG } \\
\hline Intraventricular defects of conduction & & 0 & 0 & 0 & 10 & 12 \\
\hline Electrically inactive area & & 0 & 0 & 0 & 3 & 9 \\
\hline \multirow[t]{3}{*}{ Symptoms } & Chest pain & 0 & 2 & 4 & 6 & 9 \\
\hline & Palpitations & 0 & 3 & 4 & 5 & 9 \\
\hline & Syncope & 0 & 0 & 0 & 3 & 8 \\
\hline CHF & & & 0 & 0 & 0 & 12 \\
\hline Death & & 0 & 0 & 0 & 0 & $2 *$ \\
\hline $\begin{array}{l}\text { LVDDI - left ventricular end-diastolic d } \\
\text { fraction. Symptoms and electrocardiogra } \\
\text { * One patient had sudden death (tachy } \\
\text { the Chagas' Heart Disease Service of H }\end{array}$ & $\begin{array}{l}\text { index (normal } \\
\text { rameters (ECC } \\
\text { ar) and anothe }\end{array}$ & $\begin{array}{l}\mathrm{m}^{2} \text {, abnorn } \\
\text { the numb } \\
\text { myocardia }\end{array}$ & $\begin{array}{l}b \text { above the } n \\
\text { ents; } n-\text { tota } \\
\text { (the patient }\end{array}$ & $\begin{array}{l}\text { mit - Kere } \\
\text { ents in ea } \\
\text { ake his } m\end{array}$ & $\begin{array}{l}\text { VEF - left } \\
\text { THF - cong } \\
\text { These tests }\end{array}$ & $\begin{array}{l}\text { cular ejectio } \\
\text { heart failure } \\
\text { performed a }\end{array}$ \\
\hline
\end{tabular}




\begin{tabular}{|c|c|c|c|c|c|}
\hline Total of patients & Group (Los Andes & $\begin{array}{l}\text { Electrocardiogram } \\
\text { Rest }\end{array}$ & Exercise & Dynamic (24h) (Holter) & Echocardiogram \\
\hline 15 & Healthy (N) & Normal & Rare VES & Rare VES & Normal intracavitary dimensions \\
\hline 17 & IA & Rare VES & Rare VES & $\begin{array}{c}\text { Rare VES } \\
\text { Nonrepetitive AT }\end{array}$ & Within normal limits \\
\hline 09 & IB & Rare VES & Rare VES & Rare VES & Septal and lateral akinesia \\
\hline 14 & II & $\begin{array}{l}\text { CRBB; LAHB; } \\
\text { Rare VES }\end{array}$ & $\begin{array}{l}\text { Rare VES, increasing } \\
\text { with exercise }\end{array}$ & Rare VES; NSVT & $\begin{array}{l}\text { Inferoapical akinesia; increased } \\
\text { intracavitary diameters }\end{array}$ \\
\hline 12 & $\mathrm{AF}$ & $\begin{array}{c}\text { F; anteroseptal electrically } \\
\text { inactive area }\end{array}$ & $\begin{array}{l}\text { y } \quad \mathrm{AF} \text { with low and } \\
\text { variable ventricular response } \\
\text { rare VES; salve ES }\end{array}$ & $\begin{array}{l}\text { AF with low response; } \\
\text { rare ESV; salve ES }\end{array}$ & $\begin{array}{l}\text { Diffuse akinesia; severe systolic } \\
\text { dysfunction; increased } \\
\text { intracavitary diameters }\end{array}$ \\
\hline
\end{tabular}

\begin{tabular}{|c|c|c|c|c|c|c|}
\hline \multicolumn{7}{|c|}{ Table III - Comparison of the resting measurements } \\
\hline Variables & Units & $\begin{array}{l}\text { Healthy } \\
(\mathrm{n}=15)\end{array}$ & $\begin{array}{c}\mathrm{IA} \\
(\mathrm{n}=17)\end{array}$ & $\begin{array}{c}\mathrm{IB} \\
(\mathrm{n}=9)\end{array}$ & $\begin{array}{c}\mathrm{II} \\
(\mathrm{n}=14)\end{array}$ & $\begin{array}{c}\text { III } \\
(\mathrm{n}=12)\end{array}$ \\
\hline Age & Years & $36^{\text {a.c. }} \pm 9$ & $47 \pm 11$ & $46 \pm 12$ & $52 \pm 10$ & $55 \pm 9$ \\
\hline Body mass & $\mathrm{kg}$ & $71 \pm 8$ & $77^{\circ} \pm 9$ & $67 \pm 14$ & $65 \pm 12$ & $68 \pm 13$ \\
\hline Height & $\mathrm{cm}$ & $172^{b} \pm 7$ & $169 \pm 6$ & $165 \pm 6$ & $165 \pm 7$ & $168 \pm 6$ \\
\hline $\mathrm{V}_{\text {O2rest }}$ & $\mathrm{ml} \cdot \mathrm{min}^{-1}(\mathrm{STPD})$ & $296 \pm 119$ & $323 \pm 78$ & $282 \pm 53$ & $266 \pm 90$ & $361 \pm 133$ \\
\hline $\mathrm{V}_{\text {O2rest }}^{\text {Orest }} /$ body mass & $\mathrm{ml} \cdot \mathrm{kg}^{1} \cdot \mathrm{min}^{-1}(\mathrm{STPD})$ & $4.27 \pm 1.88$ & $4.24 \pm 1.24$ & $4.28 \pm 0.68$ & $4.08 \pm 1.06$ & $5.30 \pm 1.61$ \\
\hline $\mathrm{V}_{\text {CO2rest }}^{\text {Orest }}$ & $\mathrm{ml} \cdot \min ^{-1}(\mathrm{STPD})$ & $263 \pm 125$ & $267 \pm 65$ & $222 \pm 43$ & $220 \pm 69$ & $297 \pm 115$ \\
\hline $\mathrm{R}_{\mathrm{rest}}$ & $V_{\mathrm{CO}_{2}} / V_{\mathrm{O} 2}$ & $0.87 \pm 0.15$ & $0.86 \pm 0.13$ & $0.79 \pm 0.08$ & $0.83 \pm 0.10$ & $0.82 \pm 0.10$ \\
\hline$V_{\text {Clest }}$ & ml(BTPS) & $1058^{\text {b.c. }} \pm 360$ & $915 \pm 293$ & $749 \pm 68$ & $780 \pm 161$ & $798 \pm 262$ \\
\hline$V_{\text {ICrest }}^{\text {Cr rest }}$ & $\mathrm{ml}(\mathrm{BTPS})$ & $1105^{\mathrm{c}} \pm 356$ & $969 \pm 358$ & $804 \pm 91$ & $816 \pm 143$ & $835 \pm 330$ \\
\hline $\begin{array}{l}\text { Respiratory frequency } \\
\text { Respirate }\end{array}$ & breths.min ${ }^{-1}$ & $16^{\mathrm{d}} \pm 8$ & $17^{\mathrm{d}} \pm 5$ & $18 \pm 2$ & $18 \pm 5$ & $22 \pm 5$ \\
\hline $\mathrm{V}_{\text {Erst }}$ & 1. $\min ^{-1}(\mathrm{BTPS})$ & $15 \pm 5.0$ & $16 \pm 5$ & $14 \pm 2$ & $14 \pm 2$ & $18 \pm 5$ \\
\hline $\mathrm{HR}_{\text {rest }}$ & bpm & $77 \pm 11$ & $83 \pm 14$ & $73 \pm 10$ & $72 \pm 9$ & $77 \pm 26$ \\
\hline
\end{tabular}

(patients in the initial phase of the disease). Likewise, differences between groups IA and IB and group II were not evident, because only in 2 of the 17 variables studied was a significant difference observed between these groups. Considering these results, one may assume that if the tissular changes reported in the studies analyzing biopsy material are present in a sample studied, they are not enough to determine significant changes in the functional capacity of patients with the initial phase of chronic Chagas' heart disease. In other words, clinical and laboratory findings of Chagas' disease depend on a critical mass of heart involvement. Another explanation for the results obtained could be that the dysautonomia observed in Chagas' heart disease is limited to the efferent control of the heart and, therefore, does not affect regulation of the vascular component, i. e., the regulatory disorder caused by dysautonomia impairs mechanisms of fine adjustment of the cardiovascular performance ${ }^{20}$.

Our study did not detect any significant difference in regard to the results at the end of exercise (Table IV) between groups $\mathrm{N}$ and IA and groups $\mathrm{N}$ and IB. Therefore, we assume that these patients in the initial phase of the disease still do not have a significant decrease in the maximum functional capacity as compared with healthy individuals. This result is in accordance with preceding studies ${ }^{21,22}$ that also did not show a significant difference between healthy individuals and patients in the undetermined form of Chagas' disease (group IA of the Los Andes classification) for variables during exercise. However, it does not agree with another study ${ }^{23}$. This discrepancy may reflect a greater intolerance to exercise in patients of one sample as compared with those of another sample, and even may result from factors relating to different methodologies or equipment used that may interfere with the sampling.

The values of $V_{\text {O2peak }}(\mathrm{p}=0.003)$ and $V_{\text {CO2peak }}(\mathrm{p}=0.002)$ were significantly lower in groups II and III than in group N, a fact that reflects the lower functional capacity of these patients as compared with the healthy individuals studied. This results from the inflammatory processes, degeneration, and continuous and progressive destruction of cardiac fibers, areas of fibrosis causing a reduction in the contraction power of the heart and cardiomegaly, degeneration of the intramural ganglia, and lesions of the cardiac nerves causing damage to the autonomic nervous system that are present in the more advanced stages of chronic Chagas' heart disease (groups II and III) ${ }^{24,25}$. The cardiac degenera- 


\begin{tabular}{|c|c|c|c|c|c|c|}
\hline \multicolumn{7}{|c|}{ Table IV - Comparison of the measurements during exercise } \\
\hline Variables & Unts & $\begin{array}{l}\text { Healthy } \\
(\mathrm{n}=15)\end{array}$ & $\begin{array}{c}\text { IA } \\
(n=17)\end{array}$ & $\begin{array}{c}\text { IB } \\
(n=9)\end{array}$ & $\begin{array}{c}\text { II } \\
(n=14)\end{array}$ & $\begin{array}{c}\text { III } \\
(n=12)\end{array}$ \\
\hline$V_{\text {O2pico }}$ & ml.min $\min ^{-1}$ (STP) & $2121^{\mathrm{c} \cdot \mathrm{d}} \pm 682$ & $1882^{\mathrm{d}} \pm 354$ & $1593 \pm 665$ & $1578 \pm 628$ & $1299 \pm 373$ \\
\hline$V_{\text {O2max }}^{\text {Lpico }}$ body mass & ml.kg.min ${ }^{-1}(\mathrm{STPD})$ & $31^{\mathrm{d}} \pm 12$ & $24 \pm 5$ & $23 \pm 7$ & $24 \pm 9$ & $19 \pm 5$ \\
\hline$\%_{\text {O2máx }}$ expected & $\%$ & $81^{\mathrm{b}} \pm 33$ & $72 \pm 10$ & $68 \pm 17$ & $76 \pm 24$ & $62 \pm 13$ \\
\hline$V_{\text {CO2pico }}$ & $\mathrm{ml} \cdot \mathrm{min}^{-1}(\mathrm{STPD})$ & $2493^{\mathrm{c} . \mathrm{d}} \pm 843$ & $2161^{\mathrm{d}} \pm 422$ & $1805 \pm 745$ & $1837 \pm 713$ & $1459 \pm 499$ \\
\hline $\mathrm{R}_{\text {pico }}$ & & $1.17 \pm 0.14$ & $1.15 \pm 0.06$ & $1,13 \pm 0,09$ & $1,16 \pm 0,09$ & $1.11 \pm 0.12$ \\
\hline$V_{\text {Cipico }}^{\text {suto }}$ & ml (BTPS) & $2587^{\text {b.c.d }} \pm 526$ & $2251^{\text {c.d }} \pm 461$ & $1974 \pm 470$ & $1875 \pm 423$ & $1719 \pm 343$ \\
\hline$V_{\text {Cepico }}$ & ml(BTPS) & $2651^{\mathrm{c} \cdot \mathrm{d}} \pm 695$ & $2292^{\mathrm{d}} \pm 514$ & $2108 \pm 529$ & $1895 \pm 500$ & $1776 \pm 420$ \\
\hline Respiretory frequency & breaths. $\min ^{-1}$ & $36 \pm 8$ & $39 \pm 9$ & $37 \pm 7$ & $36 \pm 9$ & $37 \pm 5$ \\
\hline $\mathrm{V}_{\text {Epico }}$ & 1. $\mathrm{min}^{-1}$ (BTPS) & $94^{\text {c.d }} \pm 21$ & $89 \pm 31$ & $77 \pm 22$ & $69 \pm 27$ & $66 \pm 16$ \\
\hline $\mathrm{HR}_{\text {pico }}$ & bmp & $167^{\text {c.d }} \pm 13$ & $157 \pm 21$ & $158 \pm 18$ & $143 \pm 24$ & $139 \pm 25$ \\
\hline$\%$ HRmax expected & $\%$ & $91 \pm 8$ & $91 \pm 12$ & $91 \pm 10$ & $86 \pm 12$ & $85 \pm 18$ \\
\hline $\mathrm{O}_{2}$ pulse $_{\text {peak }}$ & ml.beats & $13 \pm 4$ & $12 \pm 2$ & $10 \pm 3$ & $11 \pm 4$ & $10 \pm 3$ \\
\hline AT & ml.min $\min ^{-1}$ STPD) & $1509 \pm 579$ & $1577^{\text {c. d }} \pm 278$ & $1406 \pm 617$ & $1163 \pm 429$ & $1079 \pm 312$ \\
\hline AT/body mass & ml. $\mathrm{kg}^{-1} \min ^{-1}$ (STPD) & $22 \pm 9$ & $20 \pm 4$ & $21 \pm 6$ & $18 \pm 5$ & $16 \pm 4$ \\
\hline $\mathrm{AT} \%_{\text {O2peak }}$ & $\%$ & $73^{\text {c.d }} \pm 19$ & $84 \pm 7$ & $90 \pm 15$ & $77 \pm 20$ & $83 \pm 10$ \\
\hline$\%$ AT expected & $\%$ & $91 \pm 42$ & $94 \pm 13$ & $93 \pm 21$ & $87 \pm 25$ & $80 \pm 16$ \\
\hline Maximum load & Watts & $172^{\text {a.b.c.d }} \pm 22$ & $131^{\mathrm{d}} \pm 31$ & $133^{\mathrm{d}} \pm 26$ & $109 \pm 27$ & $92 \pm 18$ \\
\hline
\end{tabular}

tive process observed in chronic Chagas' heart disease limits the patient's capacity to adjust his or her cardiac output to the necessity of $\mathrm{O}_{2}$ supply to the muscles, which are enlarged during exertion, altering tolerance to exercise. This tolerance seems to be primarily determined by the reserve of cardiac output ${ }^{26}$. With a decreased capacity of $\mathrm{O}_{2}$ supply to the muscles during exercise, the patients interrupt the exercise at lower levels of $\mathrm{O}_{2}$ consumption than healthy individuals do. This fact was evident in the results of the variable maximum load $(\mathrm{p}=0.004)$ reached during exercise, in which the values of group $\mathrm{N}$ were significantly higher than those of all the other groups (Table IV). It is worth noting that the load reached by the patients in more advanced stages of the disease (group III) was also significantly lower $(p=0.001)$ than that of the patients in the initial phase of the disease (IA and IB). As the healthy group had a mean age lower than those of the patients, and considering that $\mathrm{O}_{2}$ uptake decreases as age increases, the difference between group $\mathrm{N}$ and the groups of patients may be partially justified by the variation in age observed in these groups. Considering only the groups of patients, differences in results were not influenced by age, because no significant difference was observed among these groups in regard to age.

Our study evidenced a marked difference between the most expressive variables obtained in the cardiopulmonary exercise test of the groups of patients classified in the extremes of the Los Andes classification (IA and III) (Table IV). This fact stresses the decrease in functional capacity of patients as disease progresses (fig. 1).

Normality index of $V_{\text {O2peak }}$ and prognosis of chronic Chagas' heart disease - This concept, which established that a $V_{\text {O2peak }}$ above $20 \mathrm{ml} . \mathrm{kg} \cdot \mathrm{min}^{-1}$ would represent a normality index for functional capacity in patients with heart disease ${ }^{27}$ had its application to chronic Chagas' heart disease challenged ${ }^{28}$. This occurred because the authors observed that $37 \%$ of the patients with chronic Chagas' heart disease,

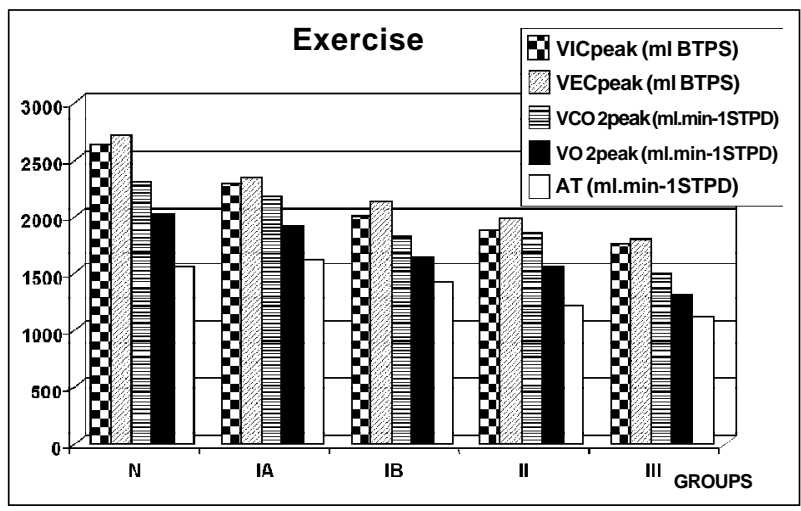

Fig. 1 - Variables measured during exercise in the groups studied. definitions in diagram I

and heart failure (group III of the Los Andes classification) reached $V_{\text {O2peak }}$ above this value. Confirming this study, we observed that $50 \%$ of the group III patients also reached values of $V_{\text {O2peak }}$ higher than $20 \mathrm{ml} . \mathrm{kg} . \mathrm{min}^{-1}$. We also observed that $V_{\text {O2peak }}$ of all the four groups of patients reached values that, according to Mady et al ${ }^{29}$, have a good survival rate. Only the group of patients with the greatest heart impairment and congestive heart failure (group III) obtained a mean $V_{\text {O2peak }}$ below $20 \mathrm{ml} . \mathrm{kg} \cdot \mathrm{min}^{-1}$ (Table IV). Only one patient (group III) out of the 52 studied obtained a $V_{\text {o2peak }}$ lower than $10 \mathrm{ml} \cdot \mathrm{kg} \cdot \mathrm{min}^{-1}, 34 \%$ of the patients reached results between 10 and $20 \mathrm{ml} . \mathrm{kg} . \mathrm{min}^{-1}$, and $52 \%$ reached results above $20 \mathrm{ml} . \mathrm{kg} \cdot \mathrm{min}^{-1}$. Therefore, we believe a greater number of studies about the variation of the functional capacity in patients with chronic Chagas' heart disease is necessary to obtain standards regarding these patients, because peculiarities of the disease seem to cause a response to exercise different from that of other heart diseases.

We also observed that group III patients had the lowest results for the variable $\% V_{\text {O2peak }}$ foretold for age and 
obtained through the equation of Itoh et al ${ }^{16}$, expressing the early interruption of the exercise due to limitations imposed by the disease.

$V_{\text {O2peak }}$ and body mass - Comparing only the groups of patients, we observed that even though group IA had a significantly higher body mass than group II, no significant difference was obtained in regard to analysis of $\mathrm{O}_{2}$ consumption per unit of body mass between these two groups of patients (Table IV), leading to the assumption that this difference did not interfere with the analysis. Only group $\mathrm{N}$ had a significant difference in regard to group III for the variable $\mathrm{O}_{2}$ consumption per unit of body mass (Table IV). This points out to a better capacity of $\mathrm{O}_{2}$ absorption per unit of body mass in healthy individuals as compared with that of patients in more advanced stages of chronic Chagas' heart disease.

$\mathrm{V}_{\text {ECpeak }}, \mathrm{V}_{\text {ICpeak }}$, respiratory frequency, and $V_{\text {E peak }}-$ Patients with heart disease often have ventilatory abnormalities that include structural changes, because of the increase in venous pressure, and functional changes ${ }^{25,27,30}$. Intolerance to exercise in patients with heart disease may occur due to the presence of dyspnea, which is related to tachypnea and to variations in $V_{\mathrm{E}}{ }^{27}$ due to pulmonary changes. In the present study, we observed that during exercise the respiratory frequency increased in all groups reaching maximum mean values between 36 and 39 breaths. min $^{-1}$, but no significant difference was observed between the groups. On the other hand, group $\mathrm{N}$ showed the highest mean values of $V_{\text {ECpeak }}$ and $\mathrm{V}_{\text {ICpeak }}$ and the lowest values were seen in group III. $\mathrm{V}_{\text {ICpeak }}$ values of patients in groups IB, II, and III were significantly decreased as compared with those of group N. Consequently, $V_{\text {Epeak }}$, which is the product between respiratory frequency and $\mathrm{V}_{\mathrm{ECpeak}}$, was significantly lower in group II and III patients when compared with that of group $\mathrm{N}$. When comparing the groups of patients, we observed that the decrease in $\mathrm{V}_{\mathrm{EC} \text { peak }}$ and $\mathrm{V}_{\text {ICpeak }}$ is evident in groups of patients with more advanced stages of the disease (II and III). This incapacity of the patients in mobilizing a greater current volume during exercise may reflect the presence of ventilatory changes in patients with severe

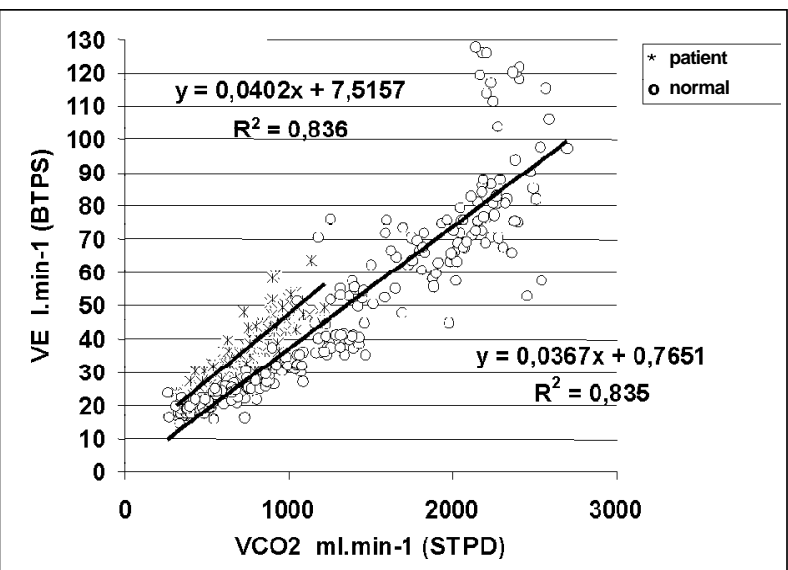

Fig. 2 - Relation between $\mathrm{V}_{\mathrm{E}}$ e $\mathrm{V}_{\mathrm{CO} 2}$ of a healthy individual and a group III patient during exercise. Note that for same level of $\mathrm{V}_{\mathrm{CO}_{2}}$ the patient has a higher $\mathrm{V}_{\mathrm{E}}$. and advanced cardiac impairment. In patients with cardiac diseases and pulmonary congestion, the respiratory pattern may be altered by interstitial congestion, with an increased respiratory frequency and decreased current volume for a given ventilatory level, as compared with healthy individuals ${ }^{27}$. Studies of patients with heart diseases other than Chagas' heart disease showed that, for the same level of $V_{\mathrm{CO}}$, these patients had an increased $V_{\mathrm{E}}$ in relation to healthy individuals. Change in the anatomical and physiologic dead spaces, which is usually present in patients with heart disease, requires a greater respiratory effort to ventilate these patients as compared with healthy individuals ${ }^{27,30}$. According to Weber et al ${ }^{27}$, this fact may be observed by the analysis of the relation between $V_{\mathrm{E}}$ and $V_{\mathrm{CO} 2}$ during exercise. Figure 2 depicts this change in the sample analyzed with the curves of $V_{\mathrm{E}}$ in relation to $\mathrm{V}_{\mathrm{CO} 2}$ of a group $\mathrm{N}$ volunteer and a group III patient. Notice that $V_{\mathrm{E}}$ increases linearly with $V_{\mathrm{CO} 2}$ in both cases, indicating that the arterial pressure of $\mathrm{C}_{\mathrm{O} 2}$ is stable, but for the same level of $V_{\mathrm{CO} 2}$, we observe more elevated values of ${ }_{E}$ for the patient in group III. This fact characterizes the ventilatory limitation of the group III patient as compared with the healthy individual.

Heart rate - In regard to heart rate during exercise $\left(\mathrm{HR}_{\text {peak }}\right)$, the significant difference results from the comparative analysis between group $\mathrm{N}$ and groups II and III, picturing an expected response. An inadequate elevation in heart rate during physical exertion is considered a characteristic of patients in advanced chronic Chagas' heart disease. It results from an autonomic dysfunction occurring due to greater parasympathetic depression as compared with the sympathetic depression, which is characteristic of the disease and aggravated by the ventricular dysfunction resulting from chronic Chagas' heart disease $22,25,31$.

Even though no significant difference was obtained for the $\mathrm{HR}_{\text {peak }}$ variable when the four groups of patients were compared, we observed that the p value ( 0.08$)$ was close to the significance level adopted in the analysis $(\mathrm{p} \leq 0.05)$. The mean $\mathrm{HR}_{\text {peak }}$ in group IA was $18 \mathrm{bpm}$ higher than that in group III. The interpretation of this result considering the approaches found in the literature in regard to the autonomic abnormalities in chronic Chagas' heart disease ${ }^{31}$ leads to the assumption that the sample studied has a mild reduction in the chronotropic response, which is a characteristic of chronic Chagas' heart disease ${ }^{31,32}$. This alteration makes it impossible for the patients, mainly those in advanced stages of the disease, to widen their tolerance to exercise by improving the chronotropic competence, i. e., the capacity of the sinus node to increase heart rate in response to metabolic necessities that increase during exercise is limited. Therefore, adjustment of the cardiac output to exercise needs, which is performed through an increase in systolic volume and in greater loads mainly by increasing heart rate, is limited in chronic Chagas' heart disease, leading to an early interruption of the exercise. The lowest values reached by groups II and III for the variable \%HRmax expected for age (Table IV) are more evidence of the limited chronotropic response of these patients. 
$\mathrm{O}_{2}$ pulse - In healthy individuals $\mathrm{O}_{2}$ pulse, which reflects systolic volume and $\mathrm{O}_{2}$ arteriovenous difference ${ }^{11}$, has higher values during exercise than it does in patients with diseases causing a reduction in systolic volume. The greatest values are found in athletes because they reach a higher $\mathrm{O}_{2}$ consumption with a lower heart rate at a given load of exercise. Even though $\mathrm{O}_{2}$ pulse did not show a significant difference between the groups in the present study, its highest values were found in group $\mathrm{N}$, and they decreased as the degree of cardiac impairment increased. This is in accordance with the characteristics of the groups studied.

Anaerobic threshold - The inadequate $\mathrm{O}_{2}$ supply during exercise causes an early imbalance between lactate production and removal, leading to metabolic acidosis and, consequently, a pH imbalance. Studies ${ }^{33}$ have shown that cellular acidosis interferes with muscle contractions and relates to fatigue and, thus, is involved with patient's tolerance to exercise.

The results of the present study show a decrease in the mean values of the anaerobic threshold of the groups as the degree of cardiac involvement increases in patients (fig. 1). The absence of a significant difference between the mean values of the anaerobic threshold in groups IA and IB indicates that the patients of the sample have ventilatory signals of metabolic acidosis in similar levels of $\mathrm{O}_{2}$ consumption. Even though the left ventricular echocardiographic changes and ejection fraction (which is slightly decreased in group IB as compared with group IA) point out the presence of incipient cardiac impairment, they were not enough to cause significant changes in the anaerobic threshold of patients in group IB as compared with those in group IA. On the other hand, the significant differences in the anaerobic threshold between the mean values in group IA (with no electrocardiographic and echocardiographic changes) and groups II (echocardiographic and electrocardiographic changes) and III (echocardiographic and electrocardiographic changes with congestive heart failure) (Table IV) indicate that in these groups cardiac changes resulting from progression of the chronic chagasic heart disease significantly altered the anaerobic threshold of the patients studied.

Analysis of the anaerobic threshold reached by the patients studied as compared with that expected for their ages allowed the conclusion that groups in the initial phase of chagasic heart disease (IA and IB) were closer to the values estimated for their ages than the groups in more advanced stages of the disease (Table IV). A progressive reduction in the anaerobic threshold with progression of the disease according to the Los Andes classification was observed.

Anaerobic threshold and body mass - Analysis of the anaerobic threshold in regard to patients' body mass did not show any significant difference between the groups with chronic chagasic heart disease for the $5 \%$ level of significance. However, as shown in table IV, this level was almost achieved $(\mathrm{p}=0.06)$. It is worth emphasizing that as recommended for ${ }_{\mathrm{O} 2}$ /body mass in a more careful analysis the patient's lean body mass should be considered and not the total body mass, which includes the fatty tissue. This variable, likewise with the others, decreases as the patient's degree of cardiac impairment increases. The result of the present study for the anaerobic threshold/body mass is in accordance with a previous study ${ }^{34}$ in which a significant difference in the anaerobic threshold/body mass was found between the extreme groups of the Los Andes classification.

In conclusion, we observed that the analysis of gas exchanges in patients at rest did not provide information that allowed an identification of responses changed due to chronic chagasic heart disease. Therefore, this technique provides no relevant information or advantage to those already used in medical practice for assessing these patients at rest.

In regard to the response to exercise, we observed that $\mathrm{V}_{\text {O2peak }}, \mathrm{V}_{\text {CO2peak }}, \mathrm{V}_{\text {ECpeak }}, \mathrm{V}_{\text {ICpeak }}$, anaerobic threshold, and maximum load are the variables that best expressed the decrease in functional capacity due to the evolution of chronic Chagas' heart disease because the results are significantly altered in the groups with more advanced stages of the disease (according to the Los Andes classification). These changes progress with worsening of the disease. As these variables represent the interaction of the entire system of $\mathrm{O}_{2}$ transport and use, we may infer that the results found reflect a progressive decrease in the functional capacity of chronic Chagas' heart disease, rendering therefore the evolution in the degree of cardiac impairment provided by the Los Andes clinical/hemodynamic classification.

\section{Acknowledgment}

We thank Rosângela Aparecida Martins Noé and Raquel Callegario Gomes of the statistical team at the Scientific Research Committee of HUCFF and the staff of the intensive care unit of the HUCFF. This study was partially funded by CNPq and PRONEX. 


\section{References}

1. Mady C, Cardoso RHA, Barretto ACP, Luz PL, Bellotti G, Pilleggi F. Survival and predictors of survival in patients with congestive heart failure due to Chagas' cardiomyopathy. Circulation, December; 1994, 90: 3098-102.

2. Faria CA. Ergometria na avaliação clínica da doença de Chagas crônica. In: Cardiopatia Chagásica. Belo Horizonte: Editora da Fundação Carlos Chagas de Pesquisa Médica, 1985: 223-65.

3. Bestetti RB. Heart transplantation as a treatment for patients whit end-stage Chagas'Heart Disease. Circulation 1997; 96: 2744-5.

4. Sullivan MJ, Hawthorne MH. Exercise intolerance in patients with chronic heart failure. Prog Cardiov Dis 1995; V XXXVIII: 1-22.

5. Carrasco HA. Diagnóstico de dano miocardico en la enfermedad de Chagas. Textos de la Universidad de los Andes. Merida: Consejo de Publicationes de la Universidad de Los Andes, 1983.

6. Medina M, Carrasco HA, Fuenmayor A, Medina A, Garcia MR. Diagnóstico po métodos no invasivos de dano ventricular izquerdo incipiente en pacientes chagásicos - utilidad de la ecocardiografia y la fonomecanografia. Archiv Inst Cardiol Méx 1980; 50: 663-9.

7. Maguirre JH, Mott KE, Souza JAA, Almeida EC, Ramos NB, Guimarães AC. Eletrocardiographic classification and abbreviated lead system for population based studies of Chagas disease. Bull Pan Am Health Org 1982; 16: 47-58.

8. Xie GE, Berk MR, Smith MD, Gurley JC, De Maria AN. Prognostic value of doppler transmitral flow patterns in patients with congestive heart failure. J Am Coll Cardiol 1994; 24: 132-9.

9. Teicholz LE, Kreulen T. Problems in echo-cardiographic volume determinations: echo-cardiographic-angiographic correlation in the present or absence of a synergy. Am J Cardiol 1976; 37: 7-11.

10. McKee PA, Castelli WP, McNamara PM, Kannel WB. The natural history of congestive heart failure. N Engl J Med 1971; 285: 1441-6.

11. Wasserman K, Hansen J, Sue DY, Whipp BJ. Principles of Exercise Testing and Interpretation. Philadelphia: Lea \& Febiger, 1987.

12. Abrantes ACS. Sistema computadorizado para monitoração cardiorrespiratória Dissertação de Mestrado, COPPE/UFRJ. Rio de Janeiro, 1997.

13. Giannella-Neto A, Bellido C, Barbosa RB, Melo MFV. Design and calibration of unicapillary pneumotachographs. J Appl Phys 1998; 84: 335-43.

14. Noguchi H, Ogushi Y, Yoshiyia I, Itakura N, Yamabayashi H. Breaht-by-breath $\mathrm{CO}_{2}$ and ${ }_{\mathrm{O} 2}$ require compensation for transport delay and dynamic response $\mathrm{J}$ Appl Phys 1982; 52: 79-84.

15. Wessel HU. Breath-by-breath variation of FRC: effect on ${ }_{\mathrm{O}_{2}}$ and $\mathrm{CO}_{2}$ measured at the mouth. Am Phys Soc 1979; 46: 1122-6.

16. Itoh $\mathrm{H}$, Taniguchi $\mathrm{K}$, Koike A, Doi M. Evaluation of severity of heart failure using ventilatory gas analysis. Circulation 1990; 81(supp 1 II): II-31 - II-7.

17. Dickstein K, Barvik S, Aarsland T, Snapinn S, Karlsson J. A comparison of methodologies in detection of the anaerobic threshold. Circulation 1990; 81: II-38-II-46.

18. Dickstein K, Barvik S, Arsland T, Svannes H, Barvik S. "A respiratory exchange ratio equal to 1 provides a reproducible index of sub-maximal cardiopulmonary exercise performance". Am J Cardiol 1993; 71: 1367-9.
19. Carrasco HA, Palácius-Prüe, Scorza CD, Molina C, Inglessis GV, Mendoza RVB Clinical, histochemical, and ultrastructural correlation in septal endomyocardial biopsies from chronic patients: Detection of early myocardial damage. Am Heart J 1987; 113: 716-24.

20. Marin-Neto JA. Alteraciones neurovegetativas cardiovasculares en la enfermedad de Chagas. Rer Fed Arg Cardiol 1988; 17: 177-89.

21. Mady C, Yazbek Jr P, Barretto ACP, et al. Estudo da capacidade funcional máxima pela ergoespirometria em pacientes portadores de doença de Chagas. Arq Bras Cardiol 1986; 47: 201-05.

22. Gallo Jr L, Morelo-Filho J, Maciel BC, Marim-Neto JA, Martins LB, Lima-Filho EC. Functional evaluation of sympathetic and parasympathetic system in Chagas ' disease using dynamic exercise. Cardiov Res 1987; 21: 922-7.

23. Mady C, Ianni BM, Arteaga E, et al. Capacidade funcional máxima e função diastólica em portadores de cardiomiopatia chagásica sem insuficiência cardíaca congestiva. Arq Bras Cardiol 1997; 69: 237-41.

24. Andrade ZA. Bases morfológicas das arritmias na miocardite chagásica In: Cardiopatia Chagásica. Belo Horizonte: Editora da Fundação Carlos Chagas de Pesquisa Médica, 1985: 79-90.

25. Manço JC, Gallo Jr L, Marin-Neto JA, Terra Filho J, Maciel BC, Amorim BDS. Alterações funcionais do sistema nervoso autônomo. In: Cardiopatia Chagásica. Belo Horizonte: Editora da Fundação Carlos Chagas de Pesquisa Médica, 1985 91-98.

26. Higginbotham MB. Systolic failure. In: Exercise and Heart Failure. Future Publishing: Armok, NY, 1997: 31-8.

27. Weber KT, Kinasewitz GT, Janicki JS, Fishman AP. Oxygen utilization and ventilation during exercise in patients with chronic cardiac failure. Circulation 1982; 65: 1213-23.

28. Mady C, Cardoso RHA, Ianni BM, et al. Capacidade funcional máxima "normal" em pacientes com insuficiência cardíaca congestiva por miocardiopatia chagásica. Arq Bras Cardiol 1996; 67: 1-4

29. Mady C, Cardoso RHA, Barreto ACP, Luz PL, Bellotti G, Pilleggi F. Survival and predictors of survival in patients with congestive heart failure due to Chagas ' cardiomyopathy. Circulation 1994; 90: 3098-102.

30. Fink LI, Wilson JR, Ferraro N. Exercise ventilation and artery wedge pressure in chronic heart failure. Am J Cardiol 1986; 57: 249-53.

31. Gallo Jr L, Marim-Neto JA, Manço JC, Rassi A, Amorim DS. Abnormal heart rate responses during exercise in patients with Chagas' disease. Cardiology 1975; 60: $147-62$.

32. Guzzetti S, Pecis M, Bonura L, Prosdocimi M, Malliani A. Impaired heart rate variability in patients with chronic Chagas' disease. Am Heart J 1992; 124 1665-6.

33. Wasserman K. Determinant and detection of anaerobic threshold and consequences of exercise above it. Circulation 1987; 76(suppl VI): VI-29 - VI-39.

34. Pedrosa RC, Melo MFV, Saad EA. Limiar anaeróbio detectado pela análise da curva-V na cardiopatia chagásica crônica. Rev Soc Bras Med Trop 1997; 30 129-38. 